\title{
The potential for reductive dehalogenation of chlorinated phenol in a sulphidogenic environment in in situ enhanced biodegradation
}

\author{
George A Ehlers* and Peter D Rose \\ Environmental Biotechnology Research Unit (EBRU), Rhodes University, PO Box 94, Grahamstown 6140, South Africa
}

\begin{abstract}
An investigation of the reductive dechlorination of 2, 4, 6-trichlorophenol (2, 4, 6-TCP) under sulphate-reducing conditions was made. Sulphate-reducing and dechloro-respiring activities were studied in a mixed microbial population operated in batch-fed as well as continuous pine chip-packed fluidised bed reactors. Results showed that reductive dechlorination of 2, 4, 6-TCP by the dechloro-respiring bacteria may be indirectly stimulated by the fermentative activity of the sulphate-reducing population affected by sulphate and lactate concentrations. Sulphate was administered in excess $\left(900 \mathrm{mg} \cdot \ell^{-1}\right)$ and limiting $\left(110 \mathrm{mg} \cdot \ell^{-1}\right)$ concentrations. At these concentrations, $\mathrm{SO}_{4}{ }^{2-}$ was available in quantities sufficient and lower than that required to bring about consumption of lactate. Transformation to 2,4-dichlorophenol (2,4-DCP), 4-chlorophenol (4-CP) and phenol was enhanced in sulphate-limiting conditions with average $47.7 \%$ TCP reduction compared to $11.6 \%$ in sulphate-enriched administered reactors. The potential application requirements for dechlorination under sulphate-reducing conditions for in situ biodegradation are considered. The input electron donor: $\mathrm{SO}_{4}{ }_{4}^{2-}$ ratio is manipulated to effect accelerated dechlorination rates for chlorinated organic compound-contaminated soil/groundwater bioremediation applications where oxygen is frequently limited.
\end{abstract}

Keywords: dehalo-respiration, enhanced biodegradation, reductive dechlorination, sulphate reduction, trichlorophenol

\section{Introduction}

The investigation of dehalogenation in the presence of alternative electron acceptors is a subject of some interest given that little is known about the role that these electron acceptors play in dehalo-respiration metabolism. The potential application of their activity in reductive dechlorination to bio-remediate chlorinated compound-contaminated soil and groundwater has not been actively considered.

Anaerobic dehalogenation reactions have been studied in various habitats and are generally found in environmental samples where methanogenesis occurs but they are found less frequently when sulphate or nitrate-reducing conditions predominate (Colberg, 1990; Gibson and Suflita, 1990). Since sulphate is a predominant electron acceptor, especially in marine and intertidal environments, sulphate reduction is the main pathway for carbon metabolism and may be the dominant electron acceptor influencing anaerobic degradation of haloorganic compounds (Häggblom and Young, 1995). Some reports indicate that sulphate appears to inhibit anaerobic degradation of halogenated compounds (Colberg, 1990; Gibson and Suflita, 1990). However, these studies were frequently conducted by the addition of sulphate to exclusively methanogenic-adapted cultures. These cultures were previously able to transform the

\footnotetext{
* To whom all correspondence should be addressed.

Present address: The University of Natural Resources and Applied Life Sciences Vienna, Dept. IFA-Tulln, Konrad Lorenz Str. 20, Tulln A-3430, Austria.

III +43-2272-66280-562; fax: +43-2272-66280-503;

e-mail: clark.ehlers@boku.ac.at

Received 14 April 2005; accepted in revised form 9 December 2005.
}

chlorinated compounds under said conditions but supplementing $\mathrm{SO}_{4}^{2-}$ obstructed or limited degradation. Since the micro-organisms were not acclimatised to sulphidogenic conditions, it was perhaps prematurely presumed that sulphate inhibits dechlorination.

Reports that demonstrate dehalogenation with mixed undefined cultures have been described (Cabirol et al., 1998; Häggblom and Young, 1995; Kohring et al., 1989). Some of these studies suggested the inability of a culture to dehalogenate the halogenated compounds in a sulphidogenic environment, or dehalogenation reactions were not tested under sulphate-reducing conditions though the cultures were shown to dehalogenate the halogenated compounds in the absence of sulphate. The cultures were able to utilise sulphate and other sulphur oxy-anions as electron acceptors. However, studies by Häggblom and Young (1995) and Kohring et al. (1989) that employed exclusively sulphidogenic-acclimated cultures showed that reductive dehalogenation could be coupled to sulphate reduction.

Various dehalo-respiring bacteria have since been isolated, identified and applied in pure culture studies to assess dechloro-respiring activity (De Weerd et al., 1990; Drzyzga et al., 2001; Gerritse et al., 1998). The hypothesis that reductive dechlorination by dechloro-respiring bacteria occurs in a synergetic relationship with sulphate-reducing bacteria (SRB) gained momentum after co-cultures were identified in soil contaminated with tetrachloroethylene (PCE) (Drzyzga et al., 2001; Gerritse et al., 1998). Employing a pure co-culture of the sulphate-reducing Desulfovibrio species and the dechlororespiring Desulfitobacterium frappieri TCE1 first elucidated the actual mechanism (Drzyzga et al., 2001). Recently, Drzyzga and Gottschal (2002) operated the sulphate reducer Desulfovibrio fructosivorans and D. frappieri TCE1 in 
co-culture. A syntrophic association between the sulphate reducer and dehalo-respiring bacterium via interspecies hydrogen transfer was proposed.

Though the potential for clean-up of environments contaminated with chlorinated compounds has been noted (Drzyzga and Gottschal, 2002), the application requirements to support sulphate reduction and dechlorination activities in in situ applications have not been thoroughly investigated. It is intended for reductive dechlorination to occur under sulphidogenic conditions; therefore sulphate will be supplemented as the electron acceptor. The transformation of chlorinated aromatic compounds is thermodynamically favourable with sulphate as terminal electron acceptor (Colberg, 1990). This coupled with studies which support the assumption that reductive dechlorinating bacteria and SRB often share biotopes that are contaminated with chlorinated compounds (Drzyzga et al., 2001; Gerritse et al., 1998) provided the basis for employing reductive dechlorination under sulphidogenic conditions.

In this study, the reductive dechlorination mechanism under sulphate-reducing conditions was investigated in a mixed microbial population enriched from environmental samples to assess whether the mechanism applies to an undefined culture. The potential for successful in situ enhanced dechloro-respiration during sulphate reduction and supplement requirements to optimise dechlorination rate for application purposes are discussed.

\section{Materials and methods}

\section{Enrichment procedure and batch-fed flask study}

Anaerobic enrichment cultures $(1000 \mathrm{ml})$ were set up. The inoculum $(12 \% \mathrm{v} / \mathrm{v})$ was prepared from activated sewage sludge collected from the Grahamstown Disposal Works and fresh leachate from the Aloes Hazardous Waste Co-Disposal Landfill Site, Port Elizabeth. Sterile growth medium containing (in $\mathrm{g} / \ell$ ) sodium lactate, $1.1 ; \mathrm{NH}_{4} \mathrm{Cl}, 1 ; \mathrm{Na}_{2} \mathrm{SO}_{4}, 1.3 ; \mathrm{K}_{2} \mathrm{HPO}_{4}, 0.5 ; \mathrm{CaCl}_{2} .6 \mathrm{H}_{2} \mathrm{O}$, $0.1 ; \mathrm{MgSO}_{4}, 2$; yeast extract, 1 ; ascorbic acid, 0.1 ; sodium thioglycolate, 0.1 , was introduced. Final medium $\mathrm{pH}$ was adjusted to 7.5. Total $\mathrm{SO}_{4}^{2-}$ concentration was $900 \mathrm{mg} \cdot \ell^{-1}$. At this concentration, $\mathrm{SO}_{4}^{2-}$ is at nearly twice the equimolar concentration necessary to carry out incomplete oxidation of the total amount of lactate $(10 \mathrm{mM})$ according to the equation: $2 \mathrm{CH}_{3} \mathrm{CHOHCOO}^{-}+$ $\mathrm{SO}_{4}^{2-} \rightarrow 2 \mathrm{CH}_{3} \mathrm{COO}^{-}+2 \mathrm{HCO}_{3}^{-}+\mathrm{HS}^{-}+\mathrm{H}^{+}$(Drzyzga et al., 2002). $2,4,6$-Trichlorophenol $(2,4,6$-TCP) additions were made from a filtered sterilised concentrated stock solution, typically to a final concentration of $20 \mathrm{mg} \cdot \ell^{-1}$. Flask headspaces were over-gassed with $\mathrm{N}_{2}$, sealed with butyl rubber stoppers and incubated statically in the dark at $28^{\circ} \mathrm{C}$. Gas phases of the flasks were regularly flushed with $\mathrm{N}_{2}$. Zinc acetate $\left(12.4 \mathrm{~g} \cdot \ell^{-1}\right)$ gas traps were routinely checked for zinc sulphide formation.

Upon zero sulphate detection, it was re-supplemented with $1.3 \mathrm{~g} \mathrm{Na}_{2} \mathrm{SO}_{4}$. Sodium lactate $(1.1 \mathrm{~g})$ and yeast extract $(1 \mathrm{~g})$ was also regularly added to the flasks when sulphate depletion was unsatisfactory. Stable sulphidogenic consortia were obtained from repeated dilutions $(1: 5 \mathrm{v} / \mathrm{v})$ into growth medium and by spiking each dilution with 2, 4, 6-TCP. These cultures were made in $125 \mathrm{~m} \ell$ serum bottles sealed with butyl rubber stoppers and aluminium crimp seals, and incubated in the dark at $28^{\circ} \mathrm{C}$. The dilution procedure was repeated until such time that products of TCP dechlorination were observed.

Reductive dechlorination was executed in stationary batchfed flask $(1000 \mathrm{~m} \ell)$ operation. Growth medium was applied in two $\mathrm{SO}_{4}^{2-}$ concentrations: 900 and $110 \mathrm{mg} \cdot \ell^{-1}$ (approximately $25 \%$ of equimolar $\mathrm{SO}_{4}^{2-}$ requirement) and spiked with TCP to a final concentration of $30 \mathrm{mg} \cdot \ell^{-1}$ into duplicate flasks. Upon zero or negligible sulphate concentrations, the flasks were resupplemented with $\mathrm{Na}_{2} \mathrm{SO}_{4}$ to its introductory concentration level working under a constant $\mathrm{N}_{2}$ flow. The flasks were also supplemented with lactic acid and yeast extract. A control flask was set up to investigate abiotic removal of the compound by autoclaving inoculum $(12 \% \mathrm{v} / \mathrm{v})$ and growth medium on two consecutive days before spiking with TCP from the stock solution. To investigate the dependency of dechloro-respiration on sulphate reduction, a duplicate inhibition experiment using molybdate was also set up. The cultures were amended with $20 \mathrm{mM}$ molybdate as $\mathrm{Na}_{2} \mathrm{MoO}_{4}$ and $\mathrm{Na}_{2} \mathrm{SO}_{4}$ after $\mathrm{SO}_{4}{ }^{2-}$ was reduced to negligible levels.

\section{Fluidised packed-bed reactor study}

Two cylindrical Perspex reactors $\left(6300 \mathrm{~cm}^{3}\right.$, reactor volume; $10 \mathrm{~cm}$, ID) packed with pinewood chips $(3$ to $7 \mathrm{~cm})$ to a height of $80 \%$ reactor volume were used. The reactors were inoculated from an actively dechlorinating culture $(12 \% \mathrm{v} / \mathrm{v}$, input cell concentration $155 \times 10^{7}$ cells $\cdot \mathrm{m}^{-1}$ ) in growth medium spiked with $2,4,6$-TCP to final concentration of $25 \mathrm{mg} \cdot \ell^{-1}$ introduced at $282 \mathrm{~m} \ell \cdot \mathrm{h}^{-1}$ flow rate. Recycling commenced through a bottomto-top loop at constant $35 \mathrm{~m} \ell \cdot \mathrm{h}^{-1}$ flow. The recycling continued for $20 \mathrm{~d}$ to facilitate the establishment and attachment of the consortium, thereafter, the reactors were operated in continuous mode. Feeding solution consisting of TCP-spiked growth medium was introduced. The headspace of the feed reservoir was continuously flushed with $\mathrm{N}_{2}$ at $30 \mathrm{~m} \ell \cdot h^{-1}$. The influent was introduced into the top and discharged from the bottom at $35 \mathrm{~m} \ell \cdot \mathrm{h}^{-1}$. The void fraction and hydraulic retention time (HRT) was 0.57 and $102.6 \mathrm{~h}$, respectively.

The reactors were operated identically; however, reactor outflow was continuously recycled (bottom-to-top) at $35 \mathrm{~m} \ell \cdot \mathrm{h}^{-1}$ in conjunction with discharge in Reactor 2 . Reactor headspaces were regularly flushed with $\mathrm{N}_{2}$ to evacuate hydrogen sulphide. Equilibrated steady-state conditions were established by allowing for at least three reactor culture volume changes before monitoring was commenced. Initially, the reactors were fed with a total sulphate concentration of $110 \mathrm{mg} \cdot \ell^{-1}$ and stable conditions were maintained for $20 \mathrm{~d}$ which, according to the retention time, equates to four to five complete volume changes of the liquid in the reactors. Thereafter, the sulphate level in the influent feed was increased to $900 \mathrm{mg} \cdot \ell^{-1}$ and the operation was continued for another $20 \mathrm{~d}$. The reactors were operated at room temperature $\left(\min 19^{\circ} \mathrm{C} \max 25^{\circ} \mathrm{C}\right)$ in the dark.

\section{Analytical methods}

Dechlorination products were identified by comparison with retention times of pure known standards according to Armenante et al. (1992) and Madsen and Aamand (1992). Triplicate flask and reactor liquid samples $(5 \mathrm{ml})$ were colleted at particular time intervals and extracted into ethyl acetate $(9 \mathrm{ml})$ plus $1 \mathrm{~m} \ell$ of a $1 \mathrm{mg} \cdot \ell^{-1}$ solution of naphthalene (internal standard). The procedure was repeated. The extractives were resuspended in the HPLC mobile phase $(10 \mathrm{ml})$ and filtered. The extraction efficiency measured was $\geq 92 \%$. Analyses were carried out using a Beckman HPLC (Solvent Module 126), a UV detector set at $280 \mathrm{~nm}$ and a Nova-Pak ${ }^{\circledR} \mathrm{C}_{18}$ column $(4.6 \times 250 \mathrm{~mm})$ (Waters). Acetonitrile-distilled water-acetic acid $(79: 20: 1 \mathrm{v} / \mathrm{v})$ was used as eluant at $1 \mathrm{ml} \cdot \mathrm{min}^{-1}$. Sulphate levels were quantified by HPLC anion exchange chromatography using a Waters 501 HPLC pump, a Hamilton PRP-X100 anion exchange column (150x4.1 $\mathrm{mm}$ ) and Waters conductivity detector (Model 430). p-Hydroxy- 
Figure 1

Batch-fed flask investigation showing 2, 4, 6-TCP (•), 2,4-DCP $(\mathbf{- )}, 4-C P(\mathbf{\Delta})$ and phenol $(\mathbf{X})$ concentrations (median of triplicate samples) detected in flasks supplemented with $110 \mathrm{mg} \cdot \ell^{-1}$ $\mathrm{SO}_{4}{ }^{2-}$

Figure 2

Batch-fed flask investigation showing 2, 4, 6-TCP (४), 2, 4-DCP

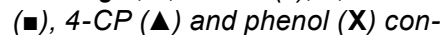
centrations (median of triplicate samples) detected in flasks supplemented with $900 \mathrm{mg} \cdot \ell^{-1} \mathrm{SO}_{4}{ }^{2-}$
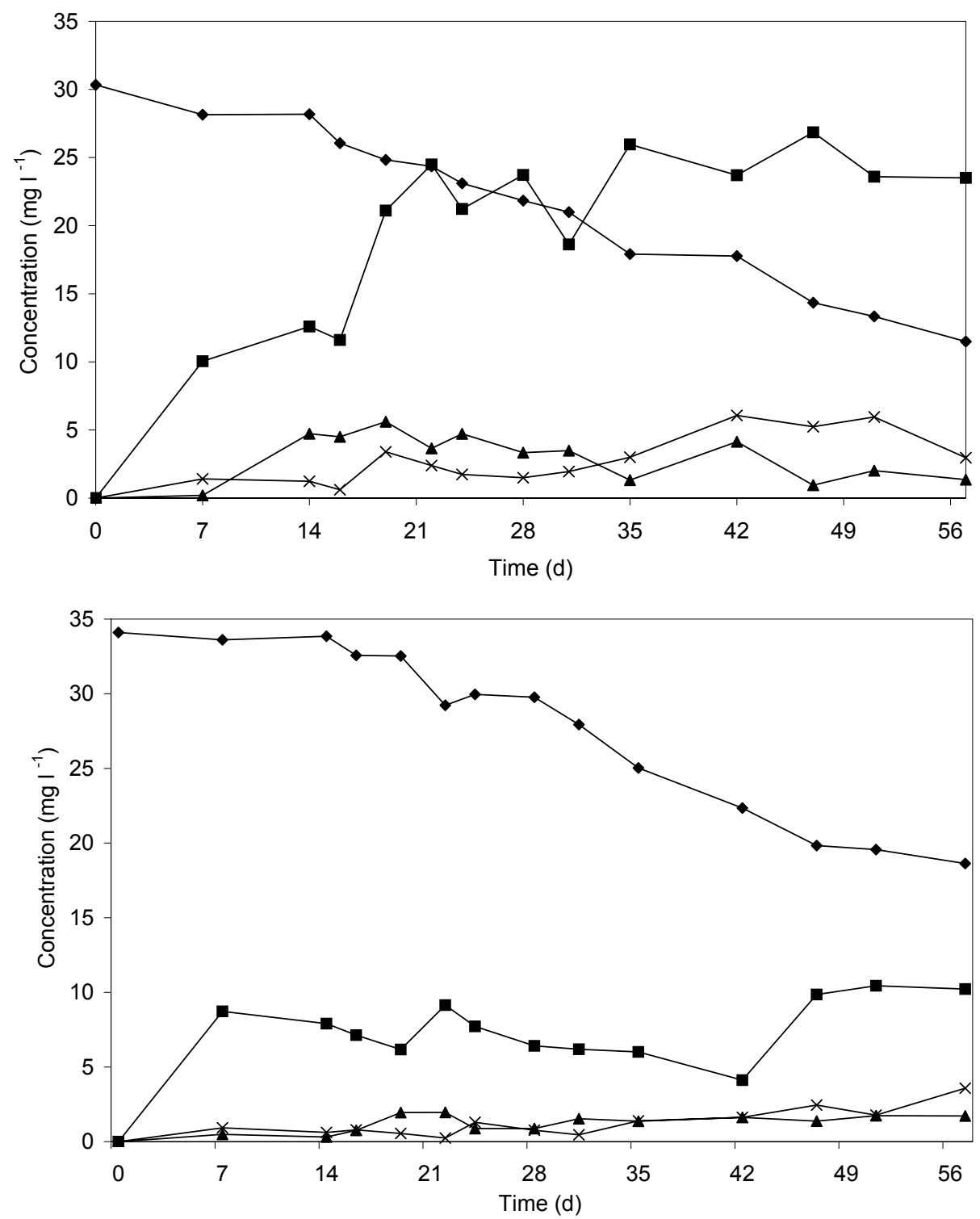

benzoic acid mobile phase (4 $\mathrm{mM}$-hydroxybenzoic acid, $2.5 \% \mathrm{v} / \mathrm{v}$ methanol, $\mathrm{pH} 8.5$ ) was used as eluant at a flow rate of $2 \mathrm{m \ell} \cdot \mathrm{min}^{-1}$. Samples were diluted using a zinc acetate (10.44 $\left.\mathrm{g} \cdot \ell^{-1}\right)$ solution and passed through two Isolute ${ }^{\circledR} \mathrm{C} 18$ (EC) columns $(25 \mathrm{mg}, 1 \mathrm{ml})$. Sulphide was quantified colorimetrically using the methylene blue method (Truper and Schlegel, 1964). Conventional plate counts for reactor liquid samples were performed employing a culture fluid (CF) medium as prescribed by Madsen and Licht (1992).

\section{Chemicals}

All chemicals were obtained from commercial sources and the highest purity available ( $>98 \%$ ) was used in each case.

\section{Results}

\section{Batch-fed flask study}

A consortium actively engaged in dechlorination of 2, 4, 6-TCP under sulphidogenic conditions was successfully enriched. Batch-fed conditions were operated for $56 \mathrm{~d}$ and 2, 4, 6-TCP was reduced by $62.1 \%$ during the operation of the sulphatelimiting $\left(110 \mathrm{mg} \cdot \ell^{-1}\right)$ flasks (Fig. 1) compared to $45.3 \%$ in sulphate-enriched flasks (Fig. 2). Dechlorination products, 2, 4dichlorophenol (2, 4-DCP), 4-chlorophenol (4-CP) and phenol, were detected in culture fluids. 2, 4-DCP accumulation was evident especially in flasks with sulphate-deficient load. Sulphide accumulated in the flasks with concentrations up to 247.0 and $537.1 \mathrm{mg} \cdot \ell^{-1}$ was detected in sulphate-limiting and enriched flasks, respectively. $4 \%$ of the introduced TCP concentration was lost in the control due to abiotic processes during a $30 \mathrm{~d}$ period. No dechlorination metabolites were detected. Molybdate-spiked flasks showed no sulphate reduction or TCP transformation for a $35 \mathrm{~d}$ period (data not shown). Molybdate inhibited sulphate reduction and with no TCP dechlorination and appearance of metabolites, the experiment indicated the possible presence of a synergetic relationship that exists between the SRB and dechloro-respiring cultures.

\section{Fluidised packed-bed reactor study}

The reactors were first fed with $110 \mathrm{mg} \cdot \ell^{-1} \mathrm{SO}_{4}^{2-}$. Figure 3 shows 2, 4, 6-TCP and $\mathrm{SO}_{4}{ }^{2-}$ concentrations introduced and TCP, $\mathrm{SO}_{4}{ }^{2-}$ 


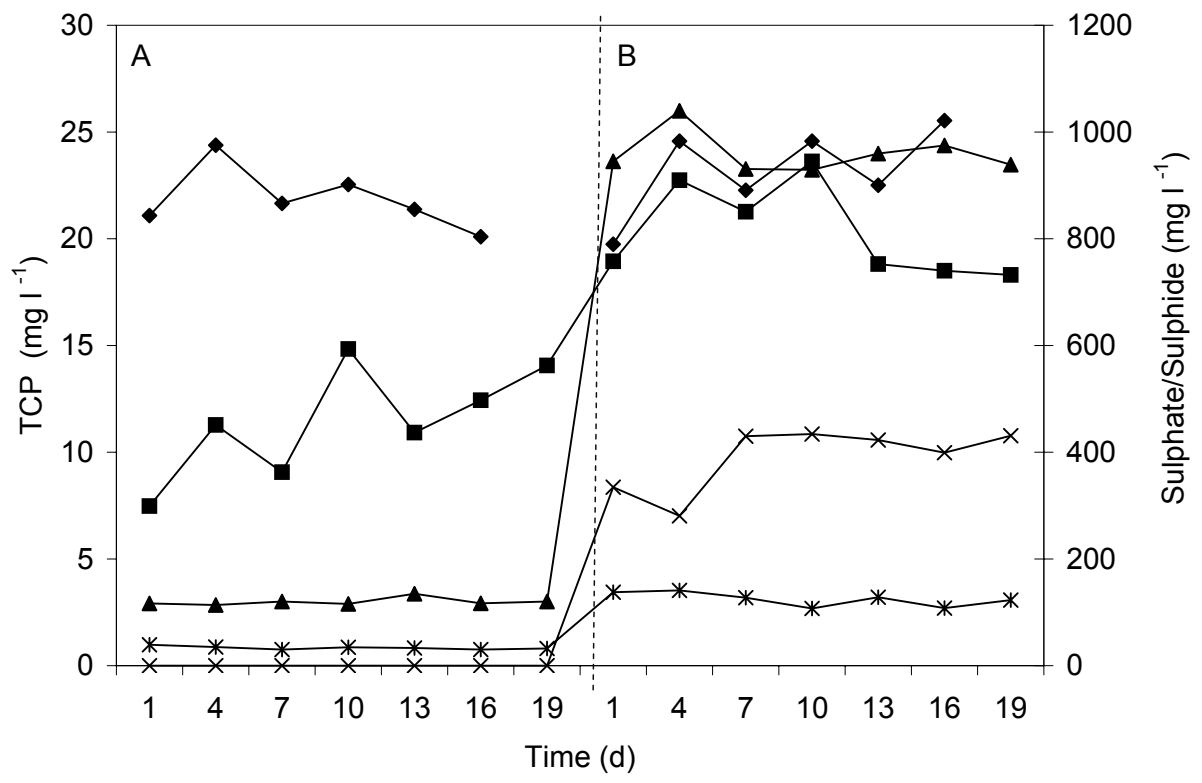

Figure 3

Influent (४) and outlet (-) 2,4,6-

$T C P$, influent $(\mathbf{\Delta})$ and outlet sulphate $(\mathbf{X})$ concentrations and culture fluid sulphide (Ж) concentrations (median of triplicate samples)for Reactor 1 perfused with 110 (A) and 900 (B) $m g \cdot l^{-1}$ $\mathrm{SO}_{4}^{2-}$ during 4 to 5 culture volume changes for each concentration

and sulphide concentrations measured in the Reactor 1 (continuous flow) outlet. The average TCP feed for Reactor 1 was $21.8 \mathrm{mg} \cdot \ell^{-1}$, with an average $47.7 \%$ reduction during four to five reactor culture volume changes in a sulphate-limiting environment (Table 1). This contrasts with an $11.6 \%$ reduction for the sulphate-enriched concentration feed.

Average sulphate-limiting feed outlet 2, 4-DCP concentration for Reactor 1 was $16.2 \mathrm{mg} \cdot \ell^{-1}$ which is equivalent to $90 \%$ of the theoretical DCP outlet concentration $\left(18.0 \mathrm{mg} \cdot \ell^{-1}\right)$ calculated on the premises of complete transformation of influent 2, 4, 6TCP to 2,4-DCP in agreement with molecular weight loss. The sulphate-enriched feed effected a $36.6 \%$ of theoretical 2, 4-DCP concentration $\left(19.1 \mathrm{mg} \cdot \ell^{-1}\right)$ which averaged $7.0 \mathrm{mg} \cdot \ell^{-1}$ during the reactor operation. 4-CP and phenol was also detected in Reactor 1 outlet for both sulphate-limiting and enriched feeds (Table 1).

As can be seen from Fig. 3 and Table 1, sulphate was completely reduced in the sulphate-limiting feed but not entirely reduced in the enriched feed, with a maximum of 575.8 to 610.5 $\mathrm{mg} \cdot \ell^{-1}$ consumed. $5 \mathrm{mM} \mathrm{SO}_{4}{ }^{2-}$ was needed for the incomplete oxidation of the lactate $(10 \mathrm{mM})$ by the SRB, calculated from the following equation:

$$
\begin{aligned}
2 \mathrm{CH}_{3} \mathrm{CHOHCOO}^{-}+\mathrm{SO}_{4}^{2-} \rightarrow & 2 \mathrm{CH}_{3} \mathrm{COO}^{-}+2 \mathrm{HCO}_{3}^{-}+\mathrm{HS}^{-} \\
& +\mathrm{H}^{+}(\text {Drzyzga et al., } 2002)
\end{aligned}
$$

With measured average $\mathrm{SO}_{4}^{2-}$ feed concentration of $959.7 \mathrm{mg} \cdot \ell^{-1}$ $\left(\sim 10 \mathrm{mM} \mathrm{SO}_{4}{ }^{2-}\right)$ and average outlet concentration $390.2 \mathrm{mg} \cdot \ell^{-1}$

(4.1 $\mathrm{mM} \mathrm{SO}_{4}^{2-}$ ), $5.9 \mathrm{mM}$ was consumed in the reactor. Complete depletion of $10 \mathrm{mM}$ lactate was, therefore, expected. With average $119.6 \mathrm{mg} \cdot \ell^{-1} \mathrm{SO}_{4}^{2-}$ in the feed solution, $100 \%$ was reduced and since sulphate was only available at approximately $25 \%$ of the required equimolar concentration, it can be expected that lactate was not completely used up during sulphate reduction.

Sulphide levels measured in the reactor culture fluid were below those to be predicted in relation to sulphate reduction. Theoretical HS- concentrations, calculated from $2 \mathrm{CH}_{3} \mathrm{CHOHCOO}^{-}$ $+\mathrm{SO}_{4}{ }^{2-} \rightarrow 2 \mathrm{CH}_{3} \mathrm{COO}^{-}+2 \mathrm{HCO}_{3}^{-}+\mathrm{HS}^{-}+\mathrm{H}^{+}$, were 41.2 and 196.1 $\mathrm{mg} \cdot \ell^{-1}$ for 110 and $900 \mathrm{mg} \cdot \ell^{-1} \mathrm{SO}_{4}^{2-}$ feed, respectively. This was to be expected since hydrogen sulphide was evacuated via the off-gas of the reactor headspace. The accumulation of black metal precipitates on the surface of the wood chips inside the reactor could have contributed to lower than expected culture fluid sulphide concentrations. Bacteria colony counts for the reactor effluent were $2.8 \times 10^{7}$ cells $\cdot \mathrm{m}^{-1}$ and $80 \times 10^{7}$ cells $\cdot \mathrm{m}^{\ell^{-1}}$ (110 $\mathrm{mg} \cdot \ell^{-1}$ and $900 \mathrm{mg} \cdot \ell^{-1} \mathrm{SO}_{4}^{2-}$, respectively).

Recycling together with continuous operation showed similar results for Reactor 2 (Fig. 4). Average TCP concentration detected in reactor outflow was lower $\left(11.4 \mathrm{mg} \cdot \ell^{-1}\right)$ for sulphate-limiting feed compared to sulphate-enriched operation (Table 1). 2, 4-DCP, 4-CP and phenol were also detected. When comparing reductive dechlorination performance, it can be seen that average TCP reduction was not significantly different in Reactor 1 with $47.7 \%$ removed compared to $50 \%$ in Reactor 2 for the $110 \mathrm{mg} \cdot \ell^{-1} \mathrm{SO}_{4}^{2-}$ feed. A notable difference is more evident

\section{TABLE 1}

Average 2, 4, 6-TCP and sulphate load and TCP, 2, 4-DCP, 4-CP, phenol and sulphate outlet concentrations for Reactors 1 and 2 (110 and $900 \mathrm{mg} \cdot \ell^{-1} \mathrm{SO}_{4}{ }^{2-}$ ) plus sulphide concentrations in culture fluid samples during

\begin{tabular}{|c|c|c|c|c|c|c|c|c|}
\hline Reactor & $\begin{array}{l}\text { Inlet TCPa } \\
\left(\mathrm{mg} \cdot \mathrm{e}^{-1}\right)\end{array}$ & $\begin{array}{l}\text { Outlet TCPa } \\
\left(\mathrm{mg} \cdot \mathrm{e}^{-1}\right)(\%)^{\mathrm{b}}\end{array}$ & $\begin{array}{l}\text { DCPa } \\
\left(\mathrm{mg} \cdot \mathrm{l}^{1}\right)\end{array}$ & $\begin{array}{l}\mathrm{CP}^{\mathrm{a}} \\
\left(\mathrm{mg} \cdot \ell^{-1}\right)\end{array}$ & $\begin{array}{l}\text { Phenola } \\
\left(\mathrm{mg} \cdot \mathrm{e}^{-1}\right)\end{array}$ & $\begin{array}{l}\text { Inlet SO }{ }_{4}{ }^{2-a} \\
\left(\mathrm{mg} \cdot \ell^{-1}\right)\end{array}$ & $\begin{array}{l}\text { Outlet } \mathrm{SO}_{4}^{2-a} \\
\left(\mathrm{mg} \cdot \ell^{-1}\right)(\%)^{\mathrm{b}}\end{array}$ & $\begin{array}{l}\text { HS - in cul- } \\
\text { ture fluid } \\
\left(\mathrm{mg} \cdot \ell^{-1}\right)\end{array}$ \\
\hline $1(110)$ & $21.8 \pm 1.4$ & $11.4 \pm 2.6(47.7)$ & $16.2 \pm 1.6$ & $5.5 \pm 0.8$ & $3.9 \pm 1.3$ & $119.6 \pm 7.7$ & 0 & $33.4 \pm 3.1$ \\
\hline $1(900)$ & $23.1 \pm 2.1$ & $20.4 \pm 2.2(11.6)$ & $7.0 \pm 0.9$ & $2.1 \pm 0.4$ & $0.9 \pm 0.2$ & $959.7 \pm 38.8$ & $390.2 \pm 29.3(59.3)$ & $124.2 \pm 13.2$ \\
\hline $2(110)$ & $22.8 \pm 1.1$ & $11.4 \pm 2.0(50.0)$ & $18.6 \pm 1.0$ & $5.3 \pm 1.4$ & $4.0 \pm 0.6$ & $117.9 \pm 3.9$ & 0 & $24.1 \pm 5.5$ \\
\hline $2(900)$ & $22.8 \pm 1.1$ & $18.4 \pm 1.1(19.2)$ & $7.4 \pm 0.9$ & $2.6 \pm 1.1$ & $1.1 \pm 0.3$ & $907.5 \pm 31.9$ & $375.3 \pm 55.4(58.6)$ & $173.5 \pm 20.2$ \\
\hline
\end{tabular}
four to five volume changes

\footnotetext{
a Average for triplicate samples \pm SD.
}

b $\% \mathrm{TCP} /$ sulphate reduction. 


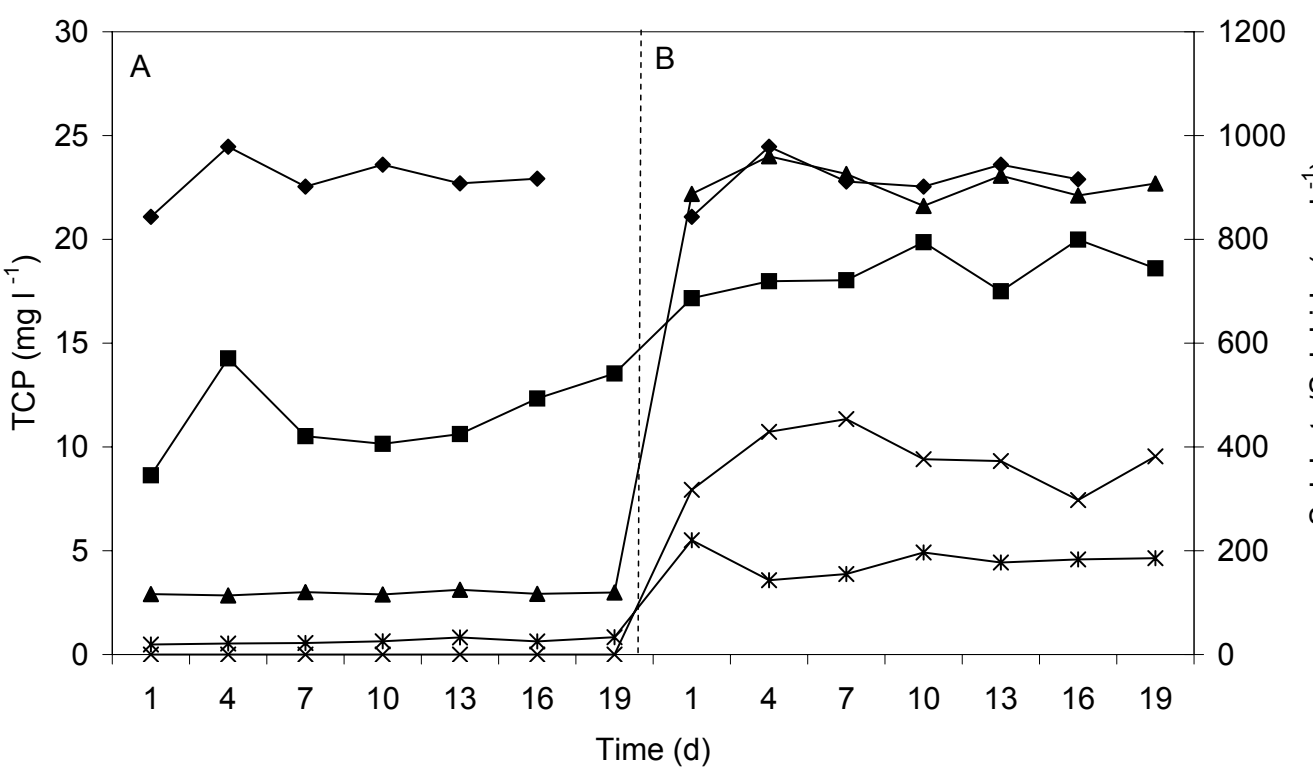

for the $900 \mathrm{mg} \cdot \ell^{-1} \mathrm{SO}_{4}^{2-}$ feed. $19.2 \% \mathrm{TCP}$ reduction was detected in Reactor 2 outlet compared to $11.6 \%$ (Reactor 1). 4-CP and phenol concentrations matched the ones detected in Reactor 1. Similar sulphate concentration decreases were detected for Reactor 2 (Table 1). Plate counts for Reactor 2 were $4.5 \times 10^{7}$ and $231 \times 10^{7}$ cells $\mathrm{m}^{-1}$ for the 110 and $900 \mathrm{mg} \cdot \ell^{-1} \mathrm{SO}_{4}^{2-}$ feeds, respectively.

\section{Discussion}

Dechlorination activity during sulphate reduction in a mixed and undefined population was shown in this study. Transformation of 2, 4, 6-TCP to 2, 4-DCP, 4-CP and phenol was accomplished by dechloro-respiring bacteria which appeared to occur in a syntrophic relationship with SRB. Dechlorination was dependent on the fermentative activity of SRB which, in turn, was affected by sulphate and lactate concentrations. Since the conditions in which sulphate was available in lesser amounts than those required to bring about incomplete consumption of total amount of lactate, it can be speculated that a combination of sulphate reduction and fermentation of lactate produce $\mathrm{H}_{2}$ equivalents which were carried out by the SRB. The fermentation of yeast extract most likely contributed as well since it has been shown to support reductive dechlorination (Madsen and Aamand, 1992). SRB, for example Desulfovibrio spp., have been shown to metabolise substrates such as lactate with concomitant production of acetate, $\mathrm{H}_{2}$ and $\mathrm{CO}_{2}$ when grown in sulphate-limiting media (Cabirol et al., 1998). The dechloro-respiring bacteria consume $\mathrm{H}_{2}$ equivalents to drive the process. The high TCP to DCP dechlorination rate and 4-CP and phenol concentrations detected for sulphate-limiting conditions were probably due to residual lactate which was fermentatively used with the release of $\mathrm{H}_{2}$ equivalents. In contrast, when sulphate is available in a concentration higher than that which is needed to consume lactate, sulphate reduction is the dominant process and no lactate, or only small amounts of lactate, are available for fermentative metabolism. Consequently, low $\mathrm{H}_{2}$ equivalents would be produced with accompanying reduced dechlorination rates as was seen in the reactor.

The supposition was made on the premise that the dechlororespiring bacteria are dependent on the fermentative activity of the SRB to produce $\mathrm{H}_{2}$ equivalents (Drzyzga et al., 2001). Molybdate was used to inhibit sulphate reduction in the batch experiment. With zero sulphate reduction (by using the competitive inhibitor), $\mathrm{SO}_{4}{ }^{2-}$ was not limited to facilitate a switchover to fermentation, thus no dechlorination occurred.

Operating Reactor 2 in recycling mode probably re-introduced low $\mathrm{H}_{2}$ equivalent concentrations from sulphate-enriched inhibited fermentation back into the reactor to drive dechlororespiration and consequently brought about the higher percentage TCP reduction.

A pH range of 6.8 to 7.9 has been shown to be optimal for dechlorination (Ning et al., 1998). $\mathrm{pH}$ for sulphate-limiting feed culture fluids for both reactors was in the range 6.28 to 6.5 compared to 6.61 to 6.9 for sulphate-enriched reactors The suggested fermentative metabolism during sulphate-limiting conditions and associated production of $\mathrm{H}_{2}$ equivalents would have effected a lower $\mathrm{pH}$ environment compared to sulphate reduction as the dominant process. Bacteria colony counts for the reactor effluent provided further insight into the consortium composition at the two sulphate influent concentrations. Sulphate reduction was the principal process occurring under sulphate-enriched conditions, therefore, SRB would be the predominant culture and hence the greater cell count. In comparison, under sulphate-limiting conditions lower cell counts (incomplete consumption of lactate) showed the dechloro-respiring culture successfully functioning together with SRB.

Drzyzga and Gottschal (2002) and others (Cabirol et al., 1998; Colberg, 1990; Drzyzga et al., 2001; 2002) have speculated about the possible role of SRB as $\mathrm{H}_{2}$-providing organisms. The results from the current investigation support the observations made by Drzyzga and Gottschal (2002) that bacterial dechloro-respiration of chlorinated aliphatic compounds (PCE used in their study) and chlorinated aromatic compounds (TCP used in this study) may be indirectly stimulated by the fermentative activity of SRB under sulphate-limiting conditions. The sulphidogenic-affected dechlorination mechanism was, therefore, shown to apply to a mixed undefined bacterial population as was reported for the two-member co-culture (Drzyzga and Gottschal, 2002).

Though deficient sulphate levels increased the rate at which chlorines are removed from the ring compound structure, it is imperative to note that interpretation of the results seems to indicate that the carbon: $\mathrm{SO}_{4}^{2-}$ ratio ultimately affects dechlorination rates and not only by managing $\mathrm{SO}_{4}^{2-}$ levels as was previously reported. The careful manipulation of the electron donor: $\mathrm{SO}_{4}^{2-}$ 
ratio should ensure the exhaustion of sulphate and reduced consumption of the carbon source to establish $\mathrm{H}_{2}$ equivalent production. The ratio of lactate: $\mathrm{SO}_{4}^{2-}$ in the current investigation was approximately 9:1 where enhanced reductive dechlorination was detected. This is lower than the required 2:1 ratio for incomplete consumption of the total amount of lactate. In situ enhanced reductive dechlorination would require the introduction of an electron donor, and, if necessary, a laboratory-acclimated culture to contaminated soil/groundwater. Sulphate concentrations in the subterranean environment could be determined to assess the need for sulphate administration. The supplementation of the contaminated zone with sulphate presents an opportunity to induce active pollutant transformation without further compromising environmental quality such as with nitrate supplements where the selection of nitrate-reducing conditions is effected, resulting in potentially toxic effects. By applying an optimum electron donor: $\mathrm{SO}_{4}{ }^{2-}$ ratio to deplete sulphate levels, accelerated dechlorination rates may be achieved.

The reductive dechlorination of 2, 4, 6-TCP is an incomplete process since degradation of phenol was not detected. A complimentary stage would therefore be a requirement. This could be accomplished as an integrated bioprocess environment where either aerobic conditions are introduced into the subterranean environment, or liquid would be pumped from below-ground to a secondary treatment unit, to mineralise the residual pollutant and its metabolites. The application of such an integrated bioprocess is being evaluated in a laboratory-scale operation, as well as molecular microbial ecology work which is currently being performed to identify the constituent species of the consortium.

\section{Acknowledgements}

The research was sponsored by the South African Water Research Commission and Rhodes University whose financial support is gratefully acknowledged.

\section{References}

ARMENANTE PM, KAFKEWITZ D, LEWANDOWSKI G an KUNG C-M (1992) Integrated anaerobic-aerobic process for the biodegradation of chlorinated aromatic compounds. Environ. Prog. 11 113-122.

CABIROL N, JACOB F, PERRIER J, FOUILLET B and CHAMBON $P$ (1998) Interactions between methanogenic and sulphate-reducing microorganisms during dechlorination of a high concentration of tetrachloroethylene. J. Gen. App. Microbiol. 44 297-301.

COLBERG PJS (1990) Role of sulfate in microbial transformations of environmental contaminants: chlorinated aromatic compounds. Geomicrobiol. J. 8 147-165.

DE WEERD KA, MANDELCO L, TANNER RS, WOESE CR and SUFLITA JM (1990) Desulfomonile tiedjei gen nov. and sp. nov., a novel anaerobic dehalogenating, sulphate-reducing bacterium. Arch. Microbiol. 154 23-30.

DRZYZGA O, EL MAMOUNI R, AGATHOS SN and GOTTSCHAL JC (2002) Dehalogenation of chlorinated ethenes and immobilization of nickel in anaerobic sediment columns under sulphidogenic conditions. Environ. Sci. Technol. 36 2630-2635.

DRZYZGA O, GERRITSE J, DIJK JA, ELISSEN H and GOTTSCHAL JC (2001) Coexistence of a sulphate-reducing Desulfovibrio species and the dehalorespiring Desulfitobacterium frappieri TCE1 in defined chemostat cultures grown with various combinations of sulphate and tetrachloroethene. Environ. Microbiol. 3 92-99.

DRZYZGA O and GOTTSCHAL JC (2002) Tetrachloroethene dehalorespiration and growth of Desulfitobacterium frappieri TCE1 in strict dependence on the activity of Desulfovibrio fructosivorans. Appl. Environ. Microbiol. 68 642-649.

GERRITSE J, ALPENAAR A and GOTTSCHAL JC (1998) Ecophysiology and application of dechlorinating anaerobes. In: Wilson TE (ed.) Water Resources and the Urban Environment. Proc. Natl. Conf. Environ. Eng. . Am. Soc. Civ. Eng. Reston. 227-232.

GIBSON SA and SUFLITA JM (1990) Anaerobic biodegradation of 2, 4, 5-thrichlorophenoxyacetic acid in samples form a methanogenic aquifer: stimulation by short-chain organic acids and alcohols. Appl. Environ. Microbiol. 56 1825-1832.

HÄGGBLOM MM and YOUNG LY (1995) Anaerobic degradation of halogenated phenols by sulphate-reducing consortia. Appl. Environ. Microbiol. 61 1546-1550.

KOHRING G-W, ZHANG X and WIEGEL J (1989) Anaerobic dechlorination of 2, 4-dichlorophenol in freshwater sediments in the presence of sulphate. Appl. Environ. Microbiol. 55 2735-2737.

MADSEN T and AAMAND J (1992) Anaerobic transformation and toxicity of trichlorophenols in a stable enrichment culture. Appl. Environ. Microbiol. 58 557-561.

MADSEN T and LICHT D (1992) Isolation and characterization of an anaerobic chlorophenol-transforming bacterium. Appl. Environ. Microbiol. 58 2874-2878.

NING Z, KENNEDY KJ and FERNANDES L (1998) pH dependency of 2, 4-chlorophenol dechlorination by anaerobic granules. Water SA 24 1153-1156.

TRUPER HG and SCHLEGEL HG (1964) Sulphur metabolism in Thiorhodaceae. Quantitative measurements on growing cells of Chromatiumokenii. Antonie Leeuwenhoek 30 225-238. 